\title{
O SISTEMA DE JUSTIÇA CRIMINAL E A PROSTITUIÇÃO NO BRASIL CONTEMPORÂNEO: administração de conflitos, discriminação e exclusão*
}

Marlene Teixeira Rodrigues**

\begin{abstract}
Resumo: A legislação penal que orienta o sistema de justiça criminal criminaliza somente atividades que impliquem em fomentar, tirar proveito ou impedir que alguém abandone a prostituição. Esse entendimento presente no Código Penal faz da polícia, instituição central no enfrentamento da questão. A continuidade dessa abordagem vai de encontro às proposições orientadas para a defesa da cidadania e dos direitos humanos daqueles que exercem a prostituição e decorre fundamentalmente da prevalência, até os dias atuais, da tendência, de grande parte da sociedade brasileira, em debater tais questões dentro do marco da moralidade.
\end{abstract}

Palavras-chave: prostituição, sistema de justiça criminal, polícia, cidadania, direitos humanos.

\section{Introdução}

Entendida objetivamente como o "comércio habitual do próprio corpo para satisfação sexual de indiscriminado número de pessoas", a prostituição não é objeto do Código Penal Brasileiro instituído pelo Decreto Lei $\mathrm{n}^{\circ} 2.848$, de 7 de dezembro de 1940 e ainda em vigor (Delmanto, 1991, p. 371). Ou seja, a legislação penal

\footnotetext{
Este artigo condensa algumas reflexões contidas na tese de doutorado Polícia e Prostituição em Brasília - um estudo de caso, apresentada ao Programa de Pós Graduação em Sociologia da Universidade de Brasília, dezembro de 2003.

** Mestre em Política Social, Doutora em Sociologia, Professora do Departamento de Serviço Social da Universidade de Brasília.
}

Artigo recebido em 10 mai. 2004; aprovados em 17 jun. 2004. 
que orienta o sistema de justiça criminal criminaliza somente atividades correlatas à prostituição. Como ocorria nos códigos anteriores, persiste o entendimento de que a prostituição em si não constitui crime. Ainda assim, ao tipificar como crime as referidas atividades, o Código Penal atribui ao sistema de justiça criminal, e em particular à polícia, papel de destaque no enfrentamento da questão. Analisaremos essa questão neste artigo, a partir da abordagem da legislação penal sobre o assunto e seus desdobramentos.

\section{Os crimes relacionados à prostituição no código penal}

O Código Penal, como mencionado, não aborda a prostituição, mas sim o lenocínio que consiste em favorecer, induzir ou tirar proveito da prostituição alheia ou ainda, manter casa de prostituição como "Crime contra os costumes". O Título VI, dedicado aos "Crimes contra os costumes", inclui, além do Capítulo V - "Do lenocínio e do tráfico de mulheres" -, capítulos referentes aos "Crimes contra a liberdade sexual" - estupro, atentado violento ao pudor, posse sexual e atentado ao pudor mediante fraude - à "Sedução e corrupção de menores" e ao "Rapto" (Brasil, Presidência..., 2002).

Vale mencionar que embora os artigos inscritos nesses últimos capítulos não se refiram direta ou indiretamente à prostituição ou ao lenocínio, muitos atingem frontalmente as mulheres que se prostituem, na medida em que têm como pré-condição para a tipificação do delito o fato de a mulher ser "honesta" e não levar "vida dissoluta". Assim, o explicitam os artigos 215, 216 e 219 que se referem, respectivamente, à "Posse sexual mediante fraude", ao "Atentado ao pudor mediante fraude" e ao "Rapto violento ou mediante fraude", e cujas vítimas são obrigatoriamente mulheres honestas.

Como destacado por Delmanto (1991, p. 351-55), a jurisprudência referente ao artigo 213, de modo similar, fixa que a viga mestra da estrutura probatória é a palavra da vítima que tem "relevante valor", caso seja honesta e de bons costumes, e que deve ser apreciada cuidadosamente, se a mesma for leviana. Nos artigos 
218, que trata da "Corrupção de menores", e 220, relativo ao rapto consensual, a jurisprudência estabelece, na mesma direção, que as menores já corrompidas moralmente e as mulheres "dissolutas" estão excluídas da proteção legal. A prevalência de valores e noções de honra tradicionais se revela ainda mais claramente nas determinações da lei penal relativas à extinção da punibilidade nos "Crimes contra os costumes", definidos nos Capítulos I, II e III do referido Título VI, mediante o casamento da vítima com o autor do delito ou com outrem. Atrela-se assim a preservação da honra feminina ao casamento.

Essas determinações legais reafirmam e convergem com as representações tradicionais vigentes em nossas sociedades que fazem com que o qualificativo honestidade difira enormemente de significado em se tratando de homens e de mulheres. Sob inspiração da tradição judaico-cristã, a respeitabilidade e honra femininas se constroem em função do controle masculino de sua sexualidade e a quebra desse monopólio masculino ameaça a honra de mulheres e homens, legitimando-se inclusive que estes últimos recorram à violência para defendê-la. Ao excluir a possibilidade de punir aqueles que cometem esses tipos de delitos contra mulheres consideradas desonestas ou de vida dissoluta, como é o caso daquelas que vivem da prostituição, a legislação penal brasileira, na prática, cassa-lhes os direitos elementares enquanto pessoas humanas e cidadãs (Escobar, 1992; Soihet, 1989; Weber \& Monteiro, 2002).

No capítulo V, do Título VI, quatro artigos - 227 a 230 - se referem ao lenocínio e um ao tráfico de mulheres -231 . Com exceção do artigo 230, referente ao rufianismo, os demais têm como objeto jurídico a defesa da "moralidade pública sexual". No caso do rufianismo, o objeto jurídico é "coibir a exploração da prostituição". Examinar-se-ão, agora, os quatro artigos referentes ao lenocínio.

O artigo 227 trata da mediação para servir à lascívia de outrem, sem qualquer referência ao sexo da pessoa. A versão comentada do Código, de Delmanto (1991, p. 369), assinala que aqui a questão central é a indução, no sentido da persuasão de alguém para satisfazer a lascívia alheia. A jurisprudência estabelece que a configuração da 
indução requer que "promessas, dádivas ou súplicas tenham sido feitas". A punição prevista na legislação é de reclusão de um a três anos. O fato de a vítima ser maior de quatorze e menor de dezoito anos ou do sujeito ativo ser parente ou responsável, faz com que a pena seja de dois a cinco anos. O uso de violência ou grave ameaça é também um agravante que faz com que a pena de reclusão passe a ser de dois a oito anos, além da pena correspondente à violência. Havendo a finalidade de lucro no cometimento do delito, a pena é acrescida de multa. Considera-se que o delito é consumado mesmo que não ocorra ejaculação.

$\mathrm{O}$ autor, remetendo a juristas consagrados, assinala ainda que embora o sujeito passivo seja qualquer pessoa sem distinção de sexo ou qualquer restrição referente à moralidade, é "por demais questionável a possibilidade de induzir pessoa já corrompida ou prostituída" (Delmanto, 1991, p. 369). Sem definição clara e objetiva do que vem a ser uma pessoa corrompida, os senões colocados pelos magistrados associam, na prática, os julgamentos à honra e à moralidade das vítimas, embora se explicite não haver qualquer restrição em relação a esta última.

O favorecimento da prostituição é tratado no artigo 228, que define o crime como a indução, facilitação ou atração de alguém à prostituição ou ainda o impedimento para que a abandone. As condutas previstas neste artigo incluem, pois, tanto o impedimento de alguém abandonar a prostituição como a indução, a atração e a facilitação para que nela ingresse, no sentido de remoção de dificuldades ou obstáculos. A punição prevista no Código é a reclusão pelo período de dois a cinco anos. Também aqui o fato de a vítima ser maior de quatorze e menor de dezoito anos, ou de o sujeito ativo ser parente ou responsável por ela, acarreta o aumento da pena de reclusão que passa a variar entre três e oito anos. Do mesmo modo, a utilização de violência, grave ameaça ou fraude aumenta a punição para um período de reclusão de quatro a dez anos, além da pena correspondente à violência. A legislação não prevê finalidade específica para o sujeito ativo, porém em caso de finalidade de lucro, à penalidade de reclusão é acrescida multa. Neste artigo, diferentemente do disposto no 227 , 
não há margem a interpretações sobre a moralidade da vítima, pois o delito existe incontestavelmente ainda quando a vítima já seja prostituída (Brasil. Presidência..., 2002).

O artigo 229 refere-se à manutenção de casa de prostituição ou lugar destinado a encontros. A ocorrência do crime independe da existência ou não de finalidade de lucro ou da mediação direta do proprietário ou do gerente. A prostituta que mantém um local para explorar o seu próprio comércio sexual não se enquadra neste crime. A punição definida é a reclusão de dois a cinco anos e a aplicação de multa aos infratores. A questão da permanência e continuidade da prática de manutenção dos locais referidos acima é fundamental neste artigo, pois já foi estabelecido pela jurisprudência que, para a tipificação do crime, exige-se a comprovação da habitualidade da conduta (Brasil. Presidência..., 2002).

Se não há muitas dúvidas no que concerne à casa de prostituição, o mesmo não ocorre com a manutenção de locais destinados a encontros libidinosos, destaca Delmanto (1991). Isto porque a redação do artigo dá margem para a adoção de um conceito amplo do que sejam tais locais para encontros libidinosos, de modo que podem abranger, além daqueles recintos voltados estritamente ao exercício da prostituição, também os motéis e hotéis de alta rotatividade. Na prática, porém, aponta ele, a tipificação do delito ocorre somente quando há prostituição. $\mathrm{O}$ mesmo autor aponta ainda que diversas decisões judiciais trataram de excluir a possibilidade de utilizar o artigo 229 para enquadrar as casas de massagem ou de banhos como locais destinados à promoção da prostituição. Uma circunstância bastante interessante considerando-se que, particularmente a partir das duas últimas décadas do século XX, uma parte substantiva desses estabelecimentos se constituiu em locais alternativos de prostituição.

$\mathrm{O}$ artigo 230 tem como objeto o rufianismo que consiste em "tirar proveito da prostituição alheia, participando diretamente de seus lucros ou fazendo-se sustentar, no todo ou em parte, por quem a exerça" (Brasil, Presidência..., 2002). Dos quatro artigos relacionados diretamente à prostituição, este é o único cujo objeto 
jurídico não é a defesa da moralidade sexual pública. Diferentemente deles, o alvo aqui é a coibição da exploração da prostituição. A penalidade prevista pela legislação é de reclusão de um a quatro anos mais multa. Esta pena passa a ser de três a seis anos caso a vítima tenha mais de quatorze e menos de dezoito anos ou se o autor é parente dela ou a tem sob sua responsabilidade. A utilização de violência ou grave ameaça é outro agravante que faz com que a pena passe a ser de dois a oito anos mais multa, e ainda a pena correspondente à violência. A questão da habitualidade da participação nos lucros auferidos com a prostituição é fundamental para a tipificação do crime (Brasil. Presidência..., 2002).

Também nesse caso, assinala Delmanto (1991), decisões judiciais definiram que o delito somente se concretiza com a participação direta nos lucros, não se caracterizando como crime o dinheiro recebido por aluguel ou o lucro em bebidas. Outro aspecto, bastante relevante, destacado pelo autor refere-se à eventual tolerância policial para com o lenocínio e o seu não rebatimento na tipificação do crime ou no enquadramento do rufião, que dela não pode se aproveitar. O fato da tolerância policial ter sido objeto de pronunciamento do Supremo Tribunal Federal é revelador de sua recorrência e das controvérsias existentes sobre a questão, a ponto de requerer um posicionamento - e de certo modo o reconhecimento dessa realidade - por parte da instância máxima do Judiciário brasileiro.

O "Tráfico de mulheres" para fins de prostituição é tratado no artigo 231. Nele se esclarece que o delito inclui a promoção ou facilitação tanto da entrada como da saída de mulher do território nacional, com vistas ao exercício da prostituição. O objeto jurídico que se defende aqui é a moralidade pública sexual, como nos artigos 227,228 e 229 . A reclusão de três a oito anos é a penalidade estabelecida quando ocorre o "delito simples". O fato de a mulher ser maior de quatorze e menor de dezoito anos ou do agente ser responsável por ela é um dos agravantes que torna o delito qualificado e que provoca o aumento da pena de reclusão para um período que varia de quatro a dez anos. $\mathrm{O}$ emprego de fraude, grave ameaça e 
violência agrava também o crime e muda a pena de reclusão para cinco a doze anos, sem excluir a penalidade própria à violência. Uma vez mais a existência de finalidade de lucro é mencionada e acresce à pena de reclusão o pagamento de multa. Não há aqui qualquer referência à moralidade ou honestidade das vítimas (Brasil. Presidência..., 2002).

Um aspecto comum aos artigos 227, 228, 231 e 229, que é tratado no $\S 3^{\circ}$ dos três primeiros e é explicitado no caput do artigo 229, merece ser destacado. Trata-se da observação ali constante acerca da existência ou não da finalidade de lucro e seus desdobramentos para o estabelecimento da punição. Do modo como está escrito na legislação penal supõe-se possível a inexistência, por parte daqueles que promovem, facilitam ou exploram a prostituição, de interesse econômico. Ora, a realidade da prostituição no período de elaboração do Código Penal como nos dias atuais torna inimaginável a circunstância em que aqueles que se mobilizam para fomentar a atividade possam fazê-lo sem visar a obtenção de lucros.

Cabe mencionar também o Capítulo VI, que tem por objeto o "Ultraje público ao pudor". Embora sem qualquer relação com a prostituição ele deve ser ressaltado, especialmente o artigo 233 que o integra e cujo foco é o "ato obsceno". A prática de ato obsceno em locais públicos, abertos ou expostos ao público constitui o cerne do crime. A legislação penal não estabelece qualquer distinção acerca do agente do crime, podendo ser qualquer pessoa, de qualquer sexo. O bem jurídico a ser protegido é o pudor público enquanto a vítima é a coletividade. Prevê-se pena de detenção de três meses a um ano que pode ser substituída por multa (Delmanto, 1991).

Há que se destacar, ainda, o artigo 233 do Código em vigor, embora na esfera judicial a imputação de sanções em referência a este artigo mostra-se difícil diante da realidade com que é confrontado. Entretanto, fora do âmbito da justiça, constata-se freqüentemente o oposto, especialmente em eventos envolvendo a prostituição. Em ocasiões assim, o artigo 233 é freqüentemente utilizado pela polícia para justificar a detenção de prostitutas que atuam nas ruas, uma vez 
que o simples exercício da atividade não implica qualquer delito previsto na norma legal. Como lembra Delmanto (1991, p. 233), no caso de travestis, a jurisprudência inclusive estabelece que incorre neste crime o homossexual que, fazendo trottoir e vestindo peças femininas, "deixa entrever seu corpo seminu". Essa mesma jurisprudência forneceu uma série de esclarecimentos relativos ao que se entende por "local público", impedindo assim que o referido artigo seja utilizado para enquadrar "práticas obscenas" realizadas no interior de veículos, porém em locais discretos, com pouco movimento e iluminação deficiente.

Esse conjunto de artigos revela pois que, embora a prostituição não seja considerada crime, a vigência até os dias atuais do supracitado Código e em consequiência, a criminalização de um conjunto variado de atividades que são intrínsecas ao seu funcionamento cotidiano, faz do sistema de justiça criminal uma instituição permanentemente demandada para determinar a existência ou não de delitos passíveis de serem punidos penalmente. Além disso, a necessidade constante de se fazer a distinção entre prostituição e lenocínio e que ocasiona o acionamento das instituições que integram o sistema de justiça criminal, abre espaço para uma série de ações que, freqüentemente, ferem direitos elementares das prostitutas quando não as envolvem em situações marcadas pele violência (Barreto, 1995; Briones, 1995; Pimentel, 1994).

A sociedade brasileira, no último quarto do século $\mathrm{XX}$, vem passando por uma série de mudanças em termos de liberação sexual e dos costumes. Esse processo não se traduziu, todavia, em alterações na nossa legislação penal como um todo e nem nos artigos referentes ao lenocínio, que permanecem sem revisão até o presente momento. A tentativa de reformulação do Código Penal ganhou força somente na última década do século XX, quando foram iniciadas discussões mais sistemáticas sobre o tema, envolvendo os Poderes Executivo, Legislativo, Judiciário e a sociedade civil. Em consequiência desse processo, foi elaborada uma proposta de reformulação do referido Código, que até o final de 2003 ainda não havia sido apreciado pelo Congresso Nacional. 


\section{Propostas de reformulação da legislação penal referente à prostituição}

Embora ainda não tenha sido implementado, o Projeto da Reforma Penal que altera a parte especial do Código Penal apresenta algumas inovações importantes. Dentre essas deve-se destacar a adoção da denominação "Crimes contra a dignidade", para se referir aos crimes de natureza sexual, em substituição a "Crimes contra os costumes", utilizada no Código de 1940. Embora possa parecer, à primeira vista, uma modificação de menor importância, tal alteração revela um deslocamento importante na percepção relacionada a esses crimes, na medida em que detém o foco no indivíduo e sua dignidade em detrimento dos costumes e das representações disseminadas na sociedade. Ao considerar os crimes sexuais como delitos contra os costumes e, portanto, contra a sociedade, o Código Penal de 1940 descaracterizou a condição de vitimização das mulheres, ignorando por completo que tais delitos, em sua maioria, constituem agressões diretas contra elas. A modificação processada no Anteprojeto corrige esse equívoco ao considerar tais crimes como delitos contra a pessoa (Brasil. Ministério da Justiça, 2002).

Os delitos relacionados à prostituição são abordados no Capítulo II, do Título II, do Anteprojeto de Lei que modifica a Parte Especial do Código Penal. Denominado "Da exploração sexual", o capítulo menciona os delitos de "Mediação para satisfazer a lascívia de outrem" (artigo 175), o "lenocínio" (artigo 176) e o "Tráfico de pessoas" (artigo 177).

O artigo 175 estabelece - de modo idêntico ao previsto no artigo 227 do Código de 1940 - que o delito consiste em "induzir alguém a satisfazer a lascívia de outrem”. A pena de reclusão, anteriormente fixada em um a três anos, é alterada no Anteprojeto para um a quatro anos, mais multa. Já no artigo 176, referente ao "lenocínio" se fez uma síntese dos delitos anteriormente incluídos nos artigos 228, 229 e 230, que tratavam, respectivamente, do "Favorecimento da prostituição", da "Casa de prostituição" e do "Rufianismo". De acordo com o texto proposto para o artigo 176, 
incorre no crime de lenocínio quem "organizar, dirigir, controlar ou tirar proveito da prostituição alheia; recrutar pessoas para encaminhá-las à prostituição; facilitá-la ou impedir que alguém a abandone" (Brasil. Ministério da Justiça, 2002). Também neste caso, a pena proposta não variou significativamente em relação ao constante no Código em vigor. Optou-se por adotar a maior penalidade prevista nos artigos 228, 229 e 230 - reclusão de dois a cinco anos, mais multa.

A confrontação dos artigos do Código Penal de 1940 com a formulação proposta no Anteprojeto de Lei revela que, embora tenha se reduzido o número de artigos na nova proposta, a formulação manteve-se praticamente idêntica a anterior. Ainda que tenha persistido a omissão em relação à prostituição, a proposta apresentada continua a criminalizar todas as atividades que, de algum modo, fornecem a infra-estrutura para o seu funcionamento. A continuidade dessa abordagem decorre fundamentalmente da prevalência, até os dias atuais, da tendência, de grande parte da sociedade brasileira, em debater tais questões dentro do marco da moralidade.

Essa constatação, a princípio, poderia soar estranha, principalmente quando se tem em conta a forte articulação e organização alcançada pelos movimentos de defesa dos direitos das "profissionais do sexo". ${ }^{2}$ Todavia, apesar do surgimento dessas organizações ter gerado inúmeros avanços, isso não significou de modo algum a eliminação da enorme gama de conflitos e divergências que cercam o tema, inclusive no campo dos movimentos feministas. Em conversa com uma assessora da ONG feminista CFEMEA que, entre outras atividades, desenvolve um trabalho de assessoria e lobby parlamentar no Congresso Nacional, em prol de temas de interesse das mulheres, foi possível constatar a controvérsia que cercou o debate em torno da questão da prostituição e do lenocínio, nas discussões referentes ao novo Código. Segundo ela, a profusão de divergências sobre $o$ assunto entre as diferentes organizações e entidades feministas, de mulheres e/ou de prostitutas, sem levar em conta opiniões "de fora", foi tamanha que a ONG optou por deixar "de molho" a 
formulação de propostas sobre o assunto, priorizando outros temas menos polêmicos.

O Capítulo II - "Da exploração sexual" - trata do "Tráfico de pessoas", no artigo 177, e do "Aumento de pena", para todos os delitos abrangidos pelo capítulo, no artigo 178 . O crime previsto no artigo 177 substitui o artigo 213 do Código de 1940 e altera a redação daquele, substituindo a palavra mulheres por pessoas, tanto no título como no texto que define o delito: "promover ou facilitar a entrada, no território nacional, de pessoa que venha exercer a prostituição, ou sua saída para exercê-la”. Há alteração também em relação à penalidade máxima estabelecida, que diminui de oito para seis anos. $\mathrm{O}$ artigo que trata do tráfico de pessoas visa somente os "terceiros" que por acaso promovam ou facilitem o trânsito de pessoas entre países para fins de prostituição. $\mathrm{O}$ tratamento dado à questão, entretanto, dá margem à punição indiscriminada de pessoas que de alguma maneira participem desse processo (e)migratório, mesmo naquelas situações em que esse translado se realiza por livre e espontânea vontade da pessoa que exerce a prostituição. Como destacado por Roberts (1998), a questão da mobilidade internacional de "profissionais do sexo", assim como da própria prostituição, é muito mais complexa do que a maneira como a legislação a aborda e faz crer. Requer, por isso, uma discussão mais aprofundada que contemple, inclusive, o direito de ir e vir das "profissionais do sexo".

O Anteprojeto de Lei dedica o terceiro e último capítulo do Título II aos delitos relacionados ao "Ultraje público ao pudor", que uma vez mais se menciona em virtude de ser prática corrente entre as forças policiais utilizarem tal artigo do Código Penal para efetuar a detenção de prostitutas em espaços públicos, quando não têm outra justificativa para fazê-lo. A única modificação em relação ao artigo que trata do tema no Código em vigor - o 233 - foi a inclusão da expressão "que cause escândalo" no texto do caput que estabelece assim que incorre em crime de "Ato obsceno" quem "praticar em lugar público, aberto ou exposto ao público, ato obsceno que cause escândalo". Não houve qualquer alteração em relação à penalidade prevista anteriormente, ou seja "detenção, de 
três meses a um ano, ou multa" (Brasil. Ministério da Justiça, 2002, p. 14).

$\mathrm{Na}$ análise da proposta inscrita no Anteprojeto de Lei, mais do que as inovações, o que se destaca é o movimento descontínuo de avanços em termos da construção da igualdade entre mulheres e homens. Essa percepção advém da constatação da persistência de alguns resquícios de noções de honra que desqualificam as mulheres, apesar dos inúmeros avanços constatados e também pela imutabilidade que prevalece nos artigos relacionados à questão da prostituição. Neste caso, em particular, chama a atenção a impermeabilidade das discussões e da redação proposta para o tratamento de questões relacionadas ao assunto às posições e pleitos expressos pelas organizações e movimentos de defesa dos direitos dos "profissionais do sexo", que ganharam destaque crescente em diferentes foros de discussão, a partir de finais da década de 1980.

As organizações de defesa dos direitos de prostitutas têm procurado ainda construir alianças com outros setores da sociedade com vistas a alcançar o reconhecimento de seus direitos e de sua condição de cidadãs. Ao incluir seus questionamentos e reivindicações na agenda pública, tais movimentos lograram, particularmente a partir da década de 1990, trazer outros setores da sociedade para a discussão de propostas relacionadas ao campo da prostituição. Muitas delas formuladas em perfeita consonância com a pauta trazida pelas organizações, enquanto outras portadoras de enfoques francamente divergentes, como se verá a seguir.

Depois de muitas décadas, em 1997, assistiu-se a uma nova tentativa de incorporar uma perspectiva "regulamentarista"3 à legislação brasileira. Um Projeto de Lei tratando do tema foi apresentado no parlamento pelo deputado federal Wigberto Tartucce, eleito pelo Distrito Federal (1994-1998) e filiado ao Partido Progressista Brasileiro, que, apesar do nome, é considerado um dos partidos mais conservadores em atuação no cenário político contemporâneo. Conforme detalhado no caput do Projeto de Lei apresentado à Câmara Federal, seu objetivo era "a regulamentação 
das atividades exercidas por pessoas que praticam a prostituição em desacordo com os costumes morais e atentatórios ao pudor" (Brasil. Câmara..., 1997, p. 1). ${ }^{4}$ Deve-se atentar para o tom moralista explicitado na proposta, logo de início, demonstrando a atualidade e vigência da percepção da prostituição como um "mal necessário". Embora o Projeto, à época de sua apresentação, tenha alcançado grande repercussão na mídia, foi arquivado sem que chegasse sequer a ser discutido por alguma das Comissões da Câmara Federal.

A mudança do estatuto legal da prostituição foi novamente colocada em pauta no Parlamento brasileiro em fevereiro 2003, quando um Projeto de Lei sobre o assunto foi apresentado ao Plenário da Câmara Federal. Elaborada, desta vez, por um deputado de esquerda e então filiado ao Partido dos Trabalhadores, o jornalista e deputado Fernando Gabeira, a proposta trata da "exigibilidade de pagamento por serviço de natureza sexual e suprime os arts. 228, 229 e 231 do Código Penal" (Brasil. Câmara..., 2003, p. 1). Como expresso nesse caput, a proposta implica uma alteração radical no modelo adotado no País para a abordagem da questão, a qual, desde as primeiras iniciativas legislativas referentes à prostituição, adotava a perspectiva de que a prostituição é um "mal necessário". Em termos concretos, isto sempre significou permitir a atividade em si e estabelecer limites ao seu exercício. Para isso optou-se, no início do século XX, por adotar mecanismos de segregação espacial e controle direto - por meio de instituições policiais e de saúde - sobre aqueles que a exerciam.

A suspensão dessas medidas não significou o abandono da referida perspectiva. Ao contrário, foi cristalizada na legislação, que se manteve alheia à prostituição propriamente dita e criminalizou todas as atividades e pessoas envolvidas com a infra-estrutura para o funcionamento do "negócio", como menciona o próprio autor do Projeto de Lei na "Justificação". Ou seja, ao propor a supressão dos artigos 228 a 231, do Código Penal de 1940, que além de constar no caput é objeto do artigo segundo, o Projeto de Lei joga por terra a solução tradicionalmente adotada pelo legislativo nacional para solucionar a paradoxal perspectiva do "mal necessário", que entende 
ser a prostituição útil apesar de moralmente reprovável, como assinalado por Castro (1993). Esta providência parece ser o ponto alto e realmente revolucionário do projeto em questão.

O referido Projeto de Lei foi objeto de uma audiência pública na Comissão de Direitos Humanos, em agosto de 2003, convocada especificamente para discuti-lo, a qual contou com a presença de representantes de entidades feministas, da Rede Nacional de Profissionais do Sexo, de universidades e órgãos governamentais que trabalham com o tema - como a Coordenação Nacional de DST/Aids, do Ministério da Saúde, e técnicos do Ministério do Trabalho que participaram das discussões na nova Classificação Brasileira de Ocupações, que recentemente incluiu o trabalho sexual dentro das atividades laborais reconhecidas pelo referido documento. Encaminhado à Comissão de Constituição e Justiça e de Redação, logo após a audiência pública, o Projeto de Lei já foi apreciado pelo relator designado, que em 30 de setembro se pronunciou "pela constitucionalidade, juridicidade e técnica legislativa, e, no mérito, pela aprovação" (Brasil. Câmara..., 2003). Não se tem notícia após este parecer que a tramitação do Projeto tenha tido prosseguimento na Câmara.

\section{O lugar da polícia frente à prostituição}

O recorrido na legislação revela a centralidade atribuída à polícia na intervenção estatal na prostituição. É a polícia que tem a competência de fazer cumprir a legislação penal e tomar parte na implementação da política de segurança pública, executando ações que previnam, reprimam e coíbam atividades de promoção e favorecimento da prostituição, além de outras consideradas atentatórias à ordem pública e aos bons costumes, previstas no Código Penal e, freqüentemente associadas àquela, (Alvarez \& Rodrigues, 2001; Briones, 1995; Escobar, 1992; Pimentel, 1994; Rago, 1991).

De um lado, temos o Código Penal em vigor, que estabelece uma série de delitos relacionados à prostituição, como abordado 
anteriormente. De outro, temos a Constituição Federal de 1988 que define como atribuições das polícias, entre outras questões, a tarefa de manter a ordem pública. No Capítulo III, do Título V, que trata "Da Defesa do Estado e das Instituições Democráticas", a Constituição estabelece que a segurança pública é um dever do Estado e direito e responsabilidade de toda a sociedade, que deve ser exercido por meio das polícias federal, rodoviária federal, civil, militar e do corpo de bombeiros militares, com vistas a preservar a ordem pública e a incolumidade das pessoas e do patrimônio (Brasil, Constituição..., art. 144, 1988).

De acordo com o $§ 4^{0}$ do artigo 144 do texto constitucional, a polícia civil, vinculada aos executivos estaduais e sob a coordenação de delegados de carreira e excluída a competência da União, tem a competência de apurar as infrações penais, excetuadas as militares, e as funções de polícia judiciária, ou seja, realizar as investigações criminais demandadas pela justiça. À polícia militar, também um dos órgãos responsáveis pela segurança pública do País e, tal como a polícia civil, subordinada ao chefe do governo estadual, compete o policiamento ostensivo e a preservação da ordem pública, conforme o $§ 5^{0}$, inciso IV do mesmo artigo (Brasil. Constituição..., 1998).

A Constituição Federal de 1988 não faz qualquer menção à defesa dos costumes e da moralidade pública, todavia, na medida em que essa questão continua associada à ordem pública, persiste o entendimento que se inclui entre as competências da polícia, especialmente da polícia militar, a quem cabe o policiamento ostensivo. De igual modo, como referido anteriormente, a legislação penal considera crime as atividades que se desenvolvem em torno da prostituição e, embora não o faça com a prostituição em si, os padrões morais hegemônicos na sociedade colocam uma série de restrições à atividade, especialmente em relação ao seu exercício público. Esta circunstância faz com que o exercício da prostituição seja freqüentemente relacionado à ordem pública, ou melhor dizendo, à desordem pública, e nesse sentido implique a constante intervenção da polícia, enquanto órgão responsável, no âmbito da segurança pública, pela manutenção da ordem. Desse contexto resulta que, dentre 
os principais canais de administração de conflitos, a polícia aparece como o mais disponível para mediar e arbitrar a relação entre os diferentes sujeitos que interagem nessa forma específica de sociabilidade que é a prostituição (Briones, 1995; Machado et al., 1999; Suárez 1999).

Ou seja, a polícia brasileira, assim como assinalado por Goldstein (1993) em relação à atuação da polícia americana, é instada a atuar em uma série de questões que embora não tenham relação com "crimes sérios", habitualmente exigem a intervenção policial porque afetam a ordem pública e o nível de sentimento de medo da comunidade.

No caso da prostituição, especialmente a denominada "prostituição pública", o que se constata no Brasil é que a intervenção policial frequientemente é demandada devido à atividade ir de encontro aos padrões de comportamentos morais sancionados socialmente, ainda que ela não se inclua entre os eventos considerados crimes pela legislação criminal. De acordo com o mesmo autor, a inexistência de alternativas de solução para vários problemas enfrentados pela população emerge, via de regra, como o determinante fundamental para o acionamento da polícia; sem que a questão de tratar-se realmente de um evento passível de ser enquadrado como crime se colocasse. De igual modo, a demanda popular não levava em consideração a competência, recursos ou capacidade policial para fazê-lo.

A perturbação da ordem pública é uma circunstância exemplar dessa demanda popular pela intervenção policial, assina Goldstein (1993). No contexto americano como no brasileiro, a atuação policial nessas ocasiões frequientemente incluía a detenção de prostitutas, mendigos e drogaditos, não obstante a falta de amparo legal para efetuá-la. O contato policial com vagabundos, consumidores de drogas e prostitutas se estabelecia, recorrentemente, com vistas a obter informação e cooperação em investigações de delitos mais graves (Goldstein, 1993). 
Objetivamente a intervenção da polícia brasileira no âmbito da prostituição está, pois, associada tanto à suspeita de existência do crime de lenocínio quanto a conflitos relacionados à perturbação da ordem pública que, embora não se caracterizem como crimes, estão em sua esfera de atuação. Essas duas vertentes da atuação policial referem-se respectivamente às atribuições da polícia civil e da polícia militar.

De acordo com Kant de Lima (1995, p. 3-8), a subdivisão das funções policiais no Brasil decorreu da necessidade de limitar o poder discricionário atribuído à polícia. A concessão de tais poderes, que constitui uma exceção dentro do sistema de justiça criminal brasileiro, está relacionada à necessidade de compatibilizar nosso sistema político igualitário com um sistema judiciário hierárquico e hierarquizado. Trata-se pois de compatibilizar a noção universalista de cidadão, contemplada pelo texto constitucional, com a concepção hierárquica de cidadania, legitimada por segmentos significativos e diferenciados da sociedade brasileira. De um lado, a função "administrativa" exercida pela polícia militar, que propicia maior liberdade à polícia, implica a vigilância da população e o conhecimento de seus criminosos potenciais, na perspectiva de prevenção da criminalidade. De outro, a função "judiciária", a cargo da polícia civil, cuja meta é auxiliar o sistema judicial no âmbito da investigação criminal, é freqüentemente "contaminada pelas funções de vigilância", o que significa, não a identificação de delitos previamente tipificados, mas a previsão de tais delitos através do recurso a estereótipos (Lima, 1995, p. 8). Essa conformação da atuação policial, identificada pelo autor, foi involuntária e claramente explicitada pelos agentes da polícia civil contactados durante o trabalho de campo, como se verá adiante.

Kant de Lima (1995) destaca também que o fato de o sistema judicial brasileiro, a quem caberia aplicar os princípios igualitários expressos na Constituição do País, ser ainda hierárquico e elitista faz com que particularize leis, originalmente genéricas, por meio de "malhas" [relações interpessoais], gerando profundas distorções. A aplicação, visivelmente desigual da lei, é orientada por critérios tais 
como a inserção profissional ou a situação social do suspeito (Lima, 1995, p. 2 et seq.). Nesse contexto, a seleção e circunscrição dos delitos bem como a construção do crime e do criminoso, operada pelos policiais, fundamenta-se num "estoque de conhecimentos" de que dispõem e que "constituem a cultura da organização e a socialização profissional", os quais, além de lhes permitir distinguir e identificar o "vagabundo" ou "bandido" do homem de bem, orientaos na busca de evidências de culpabilidade e revela, adicionalmente, seu poder na interpretação e tipificação do delito [e na construção do crime] (Paixão, 1982, p. 78 et seq.).

Em se tratando dos processos envolvendo mulheres prostitutas, a distinção entre a prostituição e o crime de lenocínio que se constrói nesse processo e em tais instâncias, revela e traduz as ambigüidades existentes no encontro das representações da prostituta nos códigos legais com os códigos de moralidade e de honra, disseminados na sociedade e partilhados pelos policiais. Na medida em que orienta suas ações por julgamentos referidos à moralidade, a polícia tende a atribuir às prostitutas o lugar de vítimas da exploração dos criminosos - os quais, na prática, quando existem, dificilmente são punidos, conforme apontado por pesquisadores que investigam o tema em outros países, como Roberts (1998) e Escobar (1992), e, no Brasil em períodos anteriores, como Rago (1987; 1989; 1991).

\section{Considerações finais}

A ação do Estado brasileiro referente à prostituição, ao reservar lugar de destaque ao sistema de justiça criminal e, dentro deste, ao aparato policial, até os dias atuais, revela que prevalece em larga medida a perspectiva do controle e da administração da atividade, embora sem desaguar propriamente na formulação de uma política pública. Essa tendência associa-se em grande medida à prevalência da percepção da prostituição enquanto um " $m a l$ " - necessário é bem verdade, mas um mal - que deve ser mantido sob estreita vigilância e controle para não colocar em perigo a sociedade. Essa situação, além de negar o reconhecimento das prostitutas como cidadãs de direitos e 
contrapor-se frontalmente ao quadro construído no âmbito das políticas de saúde, vai de encontro às alternativas construídas mais recentemente que, em consonância com a "abordagem pragmática, guiada pelo princípio de custo-benefício", buscam construir um sistema político baseado na tolerância e compromisso (Edwards, 1997, p. 57). Apesar dessa circunstância complexa e difícil na esfera da atuação policial, os avanços alcançados pelos movimentos organizados de defesa dos direitos de prostitutas têm procurado influenciar as discussões suscitadas em torno da legislação referente à questão da prostituição (Marshall \& Marshall, 1993).

As iniciativas de políticas públicas para a prostituição, na esfera do sistema de justiça criminal, embora tenham se tornado objeto de questionamento dos referidos movimentos, no último quarto do século $\mathrm{XX}$, mantiveram-se, em grande medida, isentas de alterações mais substantivas. Além disso, os paradoxos que emergiram na relação entre a justiça e a polícia, que se mostrou com cores bastante fortes, ao longo desse tempo, tampouco parecem caminhar para a superação, apesar das propostas de reformulação em discussão. Esse movimento contraditório de permanência e ruptura revela-se no surgimento dos movimentos sociais de defesa dos direitos das "profissionais do sexo", na forte presença da polícia na esfera da prostituição bem como na recorrência da violência policial contra as prostitutas. Violência, deve-se destacar, que foi um dos principais impulsionadores da emergência das referidas organizações. A simultaneidade da continuidade e da mudança coloca-se, assim, como a tônica dominante no período, iniciado no findar do século $\mathrm{XX}$ e que segue seu curso nesses primeiros anos do novo século. Seu impacto no formato da intervenção pública na prostituição e, em especial da polícia, ainda não se pode avaliar em toda sua dimensão.

\section{Notas:}

1 De acordo com Roberts (1998), a emergência do termo "trabalhadores do sexo" ou "profissionais do sexo", para se referir àqueles que exercem a prostituição ou se dedicam ao "comércio do sexo" remete ao surgimento, a partir de meados da década de 1970, dos movimentos sociais de defesa 
dos direitos desse segmento e da proposição de re-significação da prostituição, ou, melhor dizendo, do "trabalho sexual", como "um trabalho como outro qualquer".

2 De acordo com Rago (1991, p.112), o "regulamentarismo" definia a prostituição como uma "doença", um "mal" que não obstante era necessário tolerar, dentro de certos limites, uma vez que "tinha como função social canalizar os resíduos seminais masculinos, como os lixos e excrementos nos esgotos“.

3 Grifos da autora.

\begin{abstract}
The penal legislation that it guides the system of criminal justice it understands as crime the activities that imply in fomenting, taking off advantage or to hinder that somebody abandons prostitution. This present agreement in the Criminal Code makes of the police, central institution in the confrontation of the question on the part of the State. The continuity of this boarding goes of meeting to the proposals guided for the defense of the citizenship and the human rights of that they exert prostitution and elapses basically of the prevalence, until the current days, of the trend, great part of the Brazilian society, in inside debating such questions of the landmark of the morality.
\end{abstract}

Key-words: prostitution, system of criminal justice, police, citizenship, human rights.

\title{
Referências Bibliográficas
}

ALVAREZ, Gabriel; RODRIGUES, Marlene Teixeira. Prostitutas cidadãs: movimentos sociais e políticas de saúde na área de saúde (HIV/Aids). Revista de Ciências Sociais, Fortaleza, v. 32, n. 1/2, p. 53-68, 2001.

BARRETO, Lourdes. Todos calam, nós falamos. In: COMITÊ LATINO AMERICANO E DO CARIBE PARA A DEFESA DOS DIREITOS DA MULHER (CLADEM). Mulheres: vigiadas e castigadas. São Paulo: CLADEM-Brasil, 1995, p. 447-461.

A heterogeneidade da prostituição. In. SEMINÁRIO NACIONAL: PROSTITUIÇÃO E TRÁFICO DE MULHERES, 1994, Belém (PA). Anais... São Paulo: Conselho Municipal dos Direitos da Mulher de Belém; Conselho Estadual da Condição Feminina de São Paulo, 1994. p. 16-17. 
BRASIL. Comissão Especial para Reforma do Código de Processo Penal Brasileiro. Disponível em: <http://www.mj.gov.br/sal/codigo_penal/ apresenta.htm>. Acessado em: out. 2002.

. Constituição: República Federativa do Brasil. Brasília: Senado Federal, 1988.

. Câmara Federal. Projeto de Lei de 2003 (do Sr. Fernando Gabeira). Brasília: Câmara Federal, 2003. p. 1. Disponível em: <http:// 200.219.132.4/sileg/integras/114091.htm>. Acessado em: abr. 2003.

. Câmara Federal. Projeto de Lei no 3.436 de 1997. Brasília: Câmara Federal, 1997.

. Ministério da Justiça. Anteprojeto de Lei. Altera dispositivos do Código Penal e dá outras providências. Disponível em: <http:// www.mj.gov.br/imprensa/reforma.htm>. Acessado em: set. 2002.

. Presidência da República. Subchefia de Assuntos Jurídicos. DecretoLei $n^{\circ} 2.848$, de 7 de dezembro de 1940. Código Penal. Disponível em: <http://www.planalto.gov.br/ccivil_03/Decreto-Lei/ Del2848.htm>. Acessado em: nov. 2002.

BRIONES, Marena. Mulheres prostitutas: entre a tolerância e a persecução. In: COMITÊ LATINO AMERICANO E DO CARIBE PARA A DEFESA DOS DIREITOS DA MULHER (CLADEM). Mulheres: vigiadas e castigadas. São Paulo: CLADEM-Brasil, 1995. p. 419446.

CASTRO, Ricardo V. Representações sociais da prostituição na cidade do Rio de Janeiro. In: SPINK, Mary Jane (Org.). O conhecimento no cotidiano: as representações sociais na perspectiva da Psicologia Social. São Paulo: Braziliense, 1993. p. 149-187.

Delmanto, C. Código Penal Comentado e ampliado. São Paulo: Renascer, 1991.

EDWARDS, Susan. The legal regulation of prostitution: a human rights issue. In: SCAMBLER, Annette; SCAMBLER, Graham (Ed.). Rethinking prostitution: purchasing sex in the 1990s. London: Routledge, 1997. p. 57-82.

ESCOBAR, Nora S. Prostituición, genero e violência: notas para un debate. Bogotá: Unicef, 1992. Mimeografado.

GOLDSTEIN, Herman. confronting the complexity of the policing function. In: OLHIN, Lloyd E.; REMINGTON, Frank J. Discretion in Criminal Justice: the tension between individualization and uniformity. New York: State University of New York Press, 1993. p. 23-71. 
KANT DE LIMA, Roberto. A polícia da cidade do Rio de Janeiro; seus dilemas e paradoxos. 2. ed. rev. Rio de Janeiro: Forense, 1995.

MACHADO, Lia Z. et al. Relações de gênero e raça: hierarquias, poderes e violências. Brasília: Núcleo de Estudos e Pesquisas sobre a Mulher, 1999. Mimeografado. Projeto Integrado apresentado ao CNPq com o objetivo de solicitar a renovação de apoio.

MARSHALL, Chris E.; MARSHALL, Ineke H. Prostitution in the Netherlands: it's just another job! In: CULLIVER, Concetta (Ed.). Female criminality: the state of art. New York: Garland, 1993. p. 225-247.

PAIXÃO, Luiz Antônio. A organização policial numa área metropolitana. Dados, Revista de Ciências Sociais, Rio de Janeiro, v. 25, n. 1, 1982.

PIMENTEL, Sílvia. A prostituição e o Código Penal. In: SEMINÁRIO NACIONAL: PROSTITUIÇÃO E TRÁFICO DE MULHERES, 1994, Belém (PA). Anais... São Paulo: Conselho Municipal dos Direitos da Mulher de Belém; Conselho Estadual da Condição Feminina de São Paulo, 1994. p. 10-11.

RAGO, Margareth. Do cabaré ao lar: a utopia da cidade disciplinar: Brasil 1890-1930. 2. ed. Rio de Janeiro: Paz e Terra, 1987. (Coleção Estudos Brasileiros, v. 90).

. Nos bastidores da imigração: o tráfico de escravas brancas. Revista Brasileira de História, São Paulo, v. 9, n. 18, p. 145-180, 1989.

. Os prazeres da noite: prostituição e códigos da sexualidade feminina em São Paulo (1890-1930). Rio de Janeiro: Paz e Terra, 1991.

ROBERTS, Nick. As prostitutas na história. Trad. Magda Lopes. Rio de Janeiro: Record, Rosa dos Tempos, 1998.

SOIHET, Raquel. Mulheres ousadas e apaixonadas: uma investigação em processos criminais cariocas (1890-1930). Revista Brasileira de História, São Paulo, v. 9, n. 18, p. 199-216, 1989.

SUÁREZ, Mireya; BANDEIRA, Lourdes (Orgs.). Violência, gênero \& crime no Distrito Federal. Brasília: EDUnB, Paralelo XV, 1999.

ZAFFARONI, Eugenio R. Em busca das penas perdidas: a perda da legitimidade do sistema penal. Trad. Vânia Romano Pedrosa, Amir Lopez da Conceição. Rio de Janeiro: Revan, 1991.

WEBER, Demétrio; MONTEIRO, Tânia. A cada 15 segundos, uma mulher é espancada no Brasil, diz relatório. Disponível em: <http:// www.estadao.com.br/ultimas/221002.htm>. Acessado em: nov. 2002. 